\title{
Job Satisfaction among the Nurses of Makueni District Hospital, Kenya
}

\author{
Anthony Wambua Mathulu', Benard Wambua Mbithi ${ }^{2}$ \\ ${ }^{1}$ Department of Health, Government of Makueni County, Kenya \\ ${ }^{2}$ Jomo Kenyatta University of Agriculture and Technology, Kenya
}

\section{Article Info \\ Article history: \\ Received Aug 15, 2016 \\ Revised Oct 10, 2016 \\ Accepted Oct 16, 2016}

\section{Keyword:}

Health care

Hospital

Job satisfaction

Nurses

\begin{abstract}
The purpose of the study was to evaluate the level of job satisfaction among the nurses of Makueni District Hospital. This was necessitated by the high nurse staff turnover from the facility and a myriad of complains from various departments. The study was a cross sectional descriptive survey involving about 50 nurses that was carried out between 15 and $19^{\text {th }}$ July 2013 . The study employed mixed method approach. Tests of significance were through use of Chi-square, Fishers exact test and logistic regression. The key results were that overall job satisfaction was low $(36 \%)$. There were significant relationships between job satisfaction and cordial relationship with the nurse manager $\left(\chi^{2} 12.131 \mathrm{df} 4 \mathrm{p}=0.016<0.05\right.$. Logistic regression $\left.\mathrm{p}=0.018<0.05\right)$. The plans to quit the hospital and work elsewhere indicates a relationship with job satisfaction $\left(\chi^{2} 12.749\right.$ df $\left.4 \mathrm{p}=0.013<0.05\right)$. The findings of this study suggest that there is no enabling working environment for the nurses and this could be a barrier to service delivery in the Hospital. These findings suggest that the Nurse Managers should build up effective relationship with the staff and other departments and should identify negative working conditions which affect staff and appropriately delegate authority to them.
\end{abstract}

Copyright $\left({ }_{0} 2016\right.$ Institute of Advanced Engineering and Science. All rights reserved.

\section{Corresponding Author:}

Anthony Wambua Mathulu,

Department of Health,

Government of Makueni Country, Kenya.

Email: mathulu@yahoo.com, amathulu@gmail.com

\section{INTRODUCTION}

Job satisfaction is simply how people feel about their jobs and different aspects of their jobs. It is the extent to which people like (satisfaction) or dislike (dissatisfaction) their jobs [1]. Job satisfaction in health care organizations is related to many factors: optimal work arrangements; the possibility to participate actively in the decision making process; effective communication among the staff and supervisors and to be able to express freely ones opinion. Collective problem solving and the attitude of management are also important to the satisfaction of the employees [2-4].

Job satisfaction can be increased by attending to motivating factors such as making work more interesting, requiring more initiative, creativity and planning [5-6]. Managers who grasp the importance of factors affecting the well-being of staff are more likely to gain improved performance from the various groups of hospital staff. It is of utmost importance to seek the opinions of employees and include them in decision making and problem solving process [6-8].

Job satisfaction is found to be significantly linked to absenteeism and turnover. The link between job satisfaction and direct performance is found to be unequivocal. Job satisfaction in health care settings has been found to have strong direct correlation with patient satisfaction. It has become an important organizational variable in all settings and especially health care settings [9-10]. 
Burnout is one of the potential hazards occurring among individuals who do "people work". People approaching burnout begin to feel dissatisfied with their work accomplishments [11]. Evidently a person's job satisfaction is dependent of multiple factors, including but not limited to characteristics of personality, type and reputation of work, possibility to use ones skills, locus of control (i.e. where a person is located on the scale of perception of control over influential forces acting on his/her fate-whether these controls are more internal or external [12].

Makueni District Hospital which is the main referral hospital in Makueni County is faced with various challenges among them inadequate staff to provide health services to the population. During the last two years the hospital has experienced a high nurse turn over. In 2009 the nurse were about 80 but the number has dropped to around 58 with a large number now with posting orders waiting to leave the facility. The migration of nurses has resulted to deterioration of services with some departments such as the amenity being closed down. This has become a concern and hence the need to assess the job satisfaction of the nurses.

\section{RESEARCH METHOD}

The study applied a descriptive cross-sectional design that employed mixed method approach among the nurses. Qualitative data collection was through key informant interviews while quantitative data was collected using self-administrated anonymous questionnaires.

The sample size of 50 was determined using the formula by Fisher [13]; where the entire population is 10,000 or more. The study population is 58 .

$$
n=\frac{z^{2} p q}{d^{2}}
$$

Where:

$\mathrm{n}=$ desired sample size (where population is greater than 10,000)

$\mathrm{Z}=$ the standard normal deviate set at 1.96 which corresponds to the $95 \%$ confidence level.

$\mathrm{P}=$ the proportion in the target population estimates to have a particular characteristic.

$\mathrm{q}=1.0-\mathrm{p}$

$\mathrm{d}=$ degree of accuracy desired, set at .05 .

Then the sample size is:

$$
\begin{aligned}
& n=\frac{(1.96)^{2}(.5)(.5)}{(.05)^{2}} \\
& n=\frac{3.8416 \times 0.25}{0.0025} \\
& n=384
\end{aligned}
$$

If $\mathrm{N}$ (The entire population) is less than 10,000 the required sample size will be smaller. A final sample estimate ( $\mathrm{n} \mathrm{f}$ ) is calculated using the formula

$$
n f=\frac{n}{1+\left(\frac{n}{N}\right)}
$$

Therefore

$$
\begin{aligned}
& n f=\frac{384}{1+\left(\frac{384}{58}\right)} \\
& n f=\frac{384}{1+(6.62069)} \\
& n f=50
\end{aligned}
$$

All Bachelor of Science nurses, registered and enrolled nurses serving in Makueni District Hospital were eligible study subjects if they chose to participate. The nurses who were sick, on leave or those who 
chose not to participate were excluded. The sample was collected from the hospital by simple random sampling method from the list of nurses provided by the nurse manager.

Data collection was done through semi-structured questionnaires and Key informant interviews. A self-administered anonymous pre-tested questionnaire was filled by fifty nurses from various departments in Makueni District Hospital. This helped to explore individual's subjective feelings, thoughts, beliefs and perceptions towards their job satisfaction while working in Makueni Hospital. A qualitative study was done by conducting eight Key Informant Interviews.

The permission to carry out the study was sought from the Hospital Administrator. Individual nurses were requested to participate in the study but it was emphasized that participation was voluntary and anonymous. The subjects were advised not to write down their names on the questionnaires, thus ensuring anonymity and confidentiality of the study. The County Health Management Team members distributed the questionnaire in each department in the hospital did not use any form of coercion to the respondents. No rewards or monetary incentives were given to participants included in this study. Responding to the questionnaire was completely voluntary in that respondents could decide to fill in the questionnaire, if they selected so or could leave any items blank that they wished. The purposes of the research study was communicated to the nurses, and were assured that the questionnaires were to be handled ethically and the information provided was to be used to address issues that affect their performance.

Quantitative data was analyzed by using SPSS version 10.0. Cross-tabulation was used in comparison of variables. Both univariate and bivariate/multivariate analysis was used. Tests of significance were through use of Chi-square, Fishers exact test and logistic regression "enter model". A p-value less than 0.05 were deemed statistically significant. Data presentation was in frequency tables and charts. The qualitative data was analyzed by coding the main themes as expressed by the participants.

\section{RESULTS AND DISCUSSION}

3.1. Results

3.1.1. Age

The mean age of the interviewed nurses was 40.06 years while the mode was 36 years. The descriptive statistics are summarized in Table 1.

Table 1. Descriptive Statistics for Age $(n=50)$

\begin{tabular}{ccccccc}
\hline Age & $\mathrm{n}$ & Mean & Mode & SD & Minimum & Maximum \\
\hline Age in complete years & 50 & 40.06 & 36 & 9.35 & 20 & 58 \\
\hline
\end{tabular}

\subsubsection{Age Groups of Respondents}

Figure 1 summarizes the nurses interviewed by age groups.

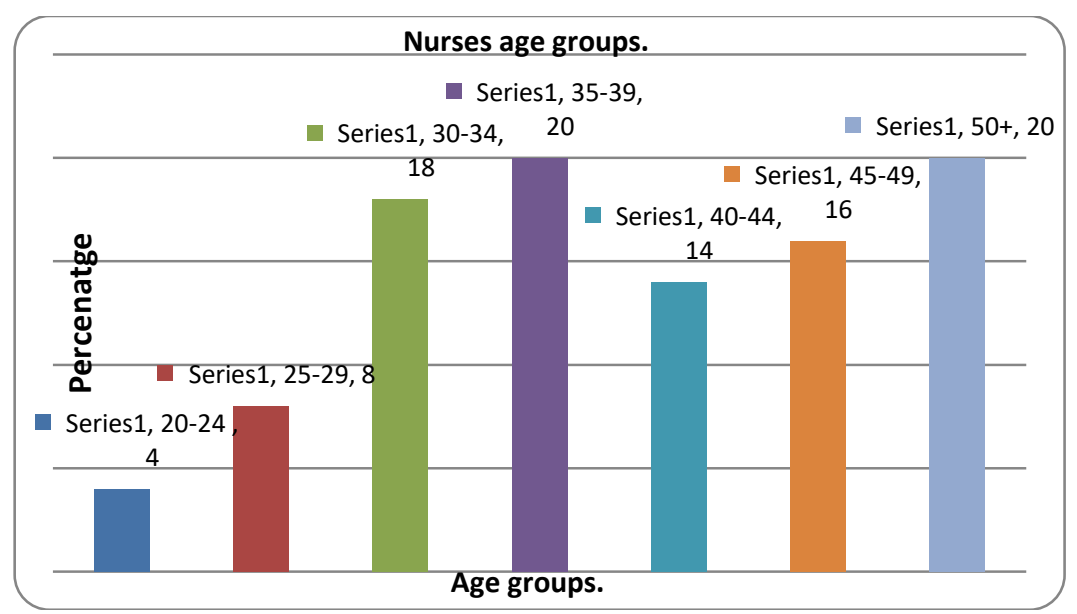

Figure 1. Nurses by Age Groups $(\mathrm{n}=50)$ 
Figure 1 indicates that most of the respondents were mainly in the 35-39(20\%) and 50 years (20\%) plus age groups. The least were $20-24$ years age group.

\subsubsection{Period of Stay in Makueni Hospital}

Figure 2 demonstrates the period of stay by the nurses in Makueni hospital.

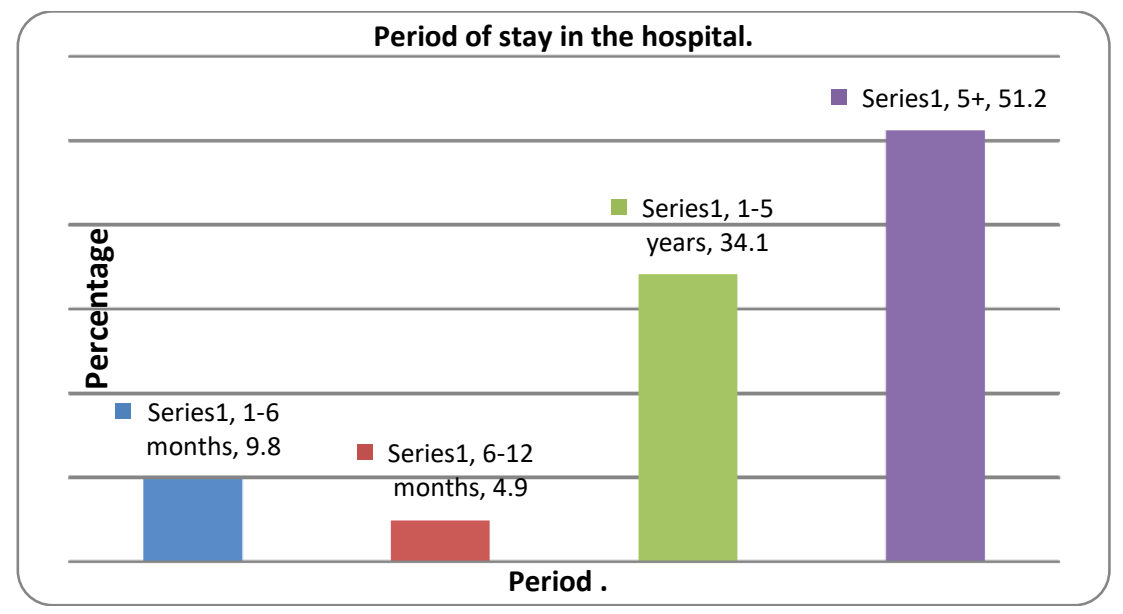

Figure 2. Nurses Period of Stay in Makueni Hospital $(n=50)$

The study data in Figure 2 demonstrates that over half $(51.2 \%)$ of the respondents worked in the hospital for more than five years only $4.9 \%$ had worked in the hospital for 6-12 months.

The study findings in Table 2 showes that more than one third (34\%) were very dissatisfied at work in the hospital. Only 6\% are very satisfied at work. More than two thirds (64\%) of the respondents were not in cordial relationship with the nursing officer in charge. According to all the key informants, the nurses are dissatisfied due to intimidation by the nursing officer and his "spies", understaffing and lack of the necessary resources required in their work. There was a significant relationship between satisfaction at work and cordial relationship with the nursing officer $\left(\mathrm{P}\right.$-value $\left.=0.016<0.05, \chi^{2} 12.131 \mathrm{df} 4\right)$. Logistic regression further indicated a significant relationship between satisfaction and cordial relationship with the nursing officer $(\mathrm{p}=0.018)$.

Table 2. Satisfaction Versus Cordial Relationship with Nursing Officer in Charge $(\mathrm{n}=50)$

\begin{tabular}{lccc}
\hline \multicolumn{1}{c}{ Satisfaction at Work } & \multicolumn{3}{c}{ Cordial Relationship with the Nursing Officer in Charge } \\
& Yes & No & Total \\
\hline Very dissatisfied & $2((4)$ & $15(30)$ & $17(34)$ \\
Rather dissatisfied & $4(8)$ & $5(10)$ & $9(18)$ \\
Neither satisfied nor dissatisfied & $1(2)$ & $6(12)$ & $7(14)$ \\
Quite satisfied & $9(18)$ & $5(10)$ & $14(28)$ \\
Very satisfied & $2(4)$ & $1(2)$ & $3(6)$ \\
Total & $18(36)$ & $32(64)$ & $50(100)$ \\
\hline
\end{tabular}

The study data in Table 3 indicates that slightly over half $(58 \%)$ of the nurses were willing to continue working in the hospital. According to the key informants those with plans to quit are running away from harsh working environment. One informant said that "In fact they are under pressure and I know of many nurses with posting orders waiting to leave" However, there was a significant relationship between plans to quit and satisfaction at work $\left(\mathrm{P}\right.$-value $\left.=0.013<0.05, \chi^{2} 12.749 \mathrm{df} 4\right)$.

Table 3. Plans to Quit Versus Satisfaction $(n=50)$

\begin{tabular}{lccc}
\hline \multicolumn{1}{c}{ Satisfaction at Work } & Yes & Plans to Quit & Total \\
\hline Very dissatisfied & $2(4)$ & $15(30)$ & $17(34)$ \\
Rather dissatisfied & $6(12)$ & $3(6)$ & $9(18)$ \\
Neither satisfied nor dissatisfied & $2(4)$ & $5(10)$ & $7(14)$ \\
Quite satisfied & $9(18)$ & $5(10)$ & $14(28)$ \\
Very satisfied & $2(4)$ & $1(2)$ & $3(6)$ \\
Total & $21(42)$ & $29(58)$ & $50(100)$ \\
\hline
\end{tabular}


The study findings in Table 4 depicts that almost half (46.4\%) leave with the pretext of going for further studies while $3.6 \%$ want to quit to either practice their areas of specialty as well have an opportunity to work in a place they can express themselves.

Table 4. Reasons for Quitting $(\mathrm{n}=28)$

\begin{tabular}{lcc}
\hline \multicolumn{1}{c}{ Reasons for Quitting } & Frequency & Percentage \\
\hline Further training & 13 & 46.4 \\
Family obligations & 4 & 14.3 \\
Practice specialty & 1 & 3.6 \\
Not given an opportunity to express oneself & 1 & 3.6 \\
Due to harsh working environment & 9 & 32.1 \\
Total & 28 & 100 \\
\hline
\end{tabular}

The findings in Table 5 shows that over half (58\%) believe that the nursing officer in charge does not have clear objectives. One the key informants believe that the nursing officer is a "boss" and not a leader who is being misled by his advisors. This has a significant relationship between perception on nursing officers objectives and the nature of relationship with the nursing officer (P-value $=0.000<0.05, \chi^{2} 22.984$ df 4 ; Logistic regression $\mathrm{p}=0.012$ ).

Table 5. Objectives by Nursing Officer in Charge $(n=50)$

\begin{tabular}{lccc}
\hline My Nursing Officer in Charge has Clear & Cordial Relationship with the Nursing Officer in Charge \\
\multicolumn{1}{c}{ Objectives } & Yes & No & Total \\
\hline Strongly disagree & $1(2)$ & $16(32)$ & $17(34)$ \\
Disagree & $2(4)$ & $10(20)$ & $12(24)$ \\
Neither agree or disagree & $2(4)$ & $3(6)$ & $5(10)$ \\
Agree & $10(20)$ & $2(4)$ & $12(24)$ \\
Strongly agree & $3(6)$ & $1(2)$ & $4(8)$ \\
Total & $18(34)$ & $32(64)$ & $50(100)$ \\
\hline
\end{tabular}

The findings in Table 6 show that about $44 \%$ have not had an opportunity to talk with the nursing officer about some difficulties that they have experienced. Only $6 \%$ have always had an opportunity to talk to him in times of difficulties. Statistical tests indicate a significant relationship between the opportunity to talk to him and the nature of relationship with the nursing officer in charge (P-value $=0.010<0.05, \chi^{2} 13.326$ df 4$)$.

Table 6. Opportunity to Talk with Nursing Officer During Difficulties $(n=50)$

\begin{tabular}{|c|c|c|c|}
\hline \multirow{2}{*}{$\begin{array}{c}\text { Opportunity to Talk to the Nursing Officer } \\
\text { about Difficulties }\end{array}$} & \multicolumn{3}{|c|}{ Cordial Relationship with the Nursing Officer in Charge } \\
\hline & Yes & No & Total \\
\hline Not at all & 4(8) & $18(36)$ & $22(44)$ \\
\hline Rarely & 2(4) & $8(16)$ & $10(20)$ \\
\hline Sometimes & $8(16)$ & $5(10)$ & $13(26)$ \\
\hline Often & $1(2)$ & $1(2)$ & 2(4) \\
\hline Always & $3(6)$ & 0 & $3(6)$ \\
\hline Total & $18(36)$ & $32(64)$ & $50(100)$ \\
\hline
\end{tabular}

Almost half (48\%) of the respondents believe that the hospital leaders are not well informed about nurses work as depicted in Table 7 . About $46 \%$ agree that the leaders are well informed about nurse work. Information about nurses work has a relationship with nature of relationship with the nursing officer (P-value $\left.=0.044<0.05, \chi^{2} 9.821 \mathrm{df} 4\right)$. 
Table 7. Leaders' Information about Nurses' work $(n=50)$

\begin{tabular}{lccc}
\hline \multicolumn{1}{c}{ Hospital Leaders are Well } & \multicolumn{2}{c}{ Cordial Relationship with the Nursing Officer in Charge } \\
Informed about Nurses Work & Yes & No & Total \\
\hline Strongly disagree & $3(6)$ & $11(22)$ & $14(28)$ \\
Disagree & $2(4)$ & $10(20)$ & $12(24)$ \\
Neither agree or disagree & 0 & $1(2)$ & $1(2)$ \\
Agree & $7(14)$ & $8(16)$ & $15(30)$ \\
Strongly agree & $6(12)$ & $2(4)$ & $8(16)$ \\
Total & $18(34)$ & $32(64)$ & $50(100)$ \\
\hline
\end{tabular}

Table 8 shows that majority $(70 \%)$ of the respondents recommend the County Health Team to introduce part time allowance while only $2 \%$ recommend employment of more health workers. Seven out of the eight key informants recommended immediate change of nursing management. The key informants believe that employment of more nurses and other health workers would also motivate the available work force.

Table 8. Recommendations for Job Satisfaction $(n=50)$

\begin{tabular}{lcc}
\hline \multicolumn{1}{c}{ Recommendations } & Frequency & Percentage \\
\hline Introduce part time allowance & 35 & 70 \\
Order more equipment and other resources & 4 & 8 \\
Discipline health workers with bad attitudes & 6 & 12 \\
Replace nursing officer in charge & 4 & 8 \\
Employ more health workers & 1 & 2 \\
Total & 50 & 100 \\
\hline
\end{tabular}

\subsection{Discussion}

The study findings indicated relationship between cordial relationship with seniors and job satisfaction. This is in agreement with a study carried out in Uganda which found that better support supervision by seniors and better team work as some of the valued incentives by $50 \%$ of the respondents [14]. Similarly another study carried out in Malawi found that poor leadership was a demotivator amongst the nurses [15]. Some managers present unrealistic demands and this is likely to affect work performance. A study in Michigan found that a higher level of teamwork and perceptions of adequate staffing leads to greater job satisfaction with current position and occupation [16]. Support supervision as opposed to traditional supervision can be an important motivator to the workers in an organization. The manager who works with their subordinates in identifying the issues affecting their well-being and involves them in decision making boosts the satisfaction of the workers. They perceive themselves as part of the organization and will do everything to ensure improved performance.

Study findings indicate that almost half $(48 \%)$ of the respondents believe that the hospital leaders are not well informed about nurses' work. This agrees with a study in Canada established that servant leadership and employee satisfaction are strongly correlated [17]. A study carried out in Machinga District Hospital in Malawi which found that the health workers leave because of poor leadership skills by their leaders [15]. These findings are similar to another study in Slovenian Hospitals which found that managerial competencies of leaders influenced nurses' job satisfaction most [18]. Servant leaders are viewed as trustees of the human capital in an organization and should cherish it for greater customer focus.

The study data shows that around $42 \%$ of the nurses were willing to leave the hospital to other health facilities. The reasons are given for wanting to leave included engaging in further studies and due to poor working environment. This finding is consistent with a study in Pakistan which found that opportunities for career development, promotional schemes of the organization have high associations with job satisfaction. However, work environment was found to have low significance towards job satisfaction [19]. This disagrees with a study in Ethiopia which found that $65.1 \%$ of health workers were dissatisfied with their job due to poor working conditions [20]. Similarly, a study in Nigeria noted a significant relationship between overall work environment and general job satisfaction of the nurses [21]. An enabling environment and professional development through continuous education motivates the health workers by building their confidence in service delivery. This guarantees the quality of care and the desired health outcomes of the patients and hence improving patient satisfaction.

The study findings indicate that majority $(70 \%)$ of the respondents' recommended part time allowance as an incentive. This mirrors the findings in a study in Malawi that indicated that health professionals in Malawi currently struggle to support themselves on their salaries [22]. This is consistent with a study in Egypt which showed that the nursing staff had statistically significant higher mean score of satisfaction on the financial reward [23]. Supplementing the income of the health workers enable to limit 
their income gap and empower them to cope with their family demands. This dissuades the workers from crude means of earning income such as stealing drugs and helps to improve their satisfaction.

\section{CONCLUSION}

The findings of this study suggest that there is no enabling working environment for the nurses and this could be a barrier to service delivery in the Hospital. The study data indicated a significant relationship between relationships between the nursing officers in charge and plans to quit the hospital by the nurses. This is considerably affecting job satisfaction and performance of the nurses and other departments at large.

\section{ACKNOWLEDGEMENTS}

We are grateful to all whose contributions made it possible to accomplish this work. We wish to convey our gratitude to the Health Administrative Officer and the Medical Superintendent of Makueni District Hospital for allowing us to administer the questionnaire to the staff. We salute the County Health Management Team members who assisted us in data collection. Last but not least, we are grateful to the nurses and departmental heads for their invaluable information. To all of you, God bless

\section{REFERENCES}

[1] Spector P. E., "Job satisfaction: Application, assessment, causes and consequences," Thousand Oaks, CA, Sage, 1997.

[2] Kivimaki M., et al., "Contributors to satisfaction with management in hospital wards," J nurs manag, 1994.

[3] Love J. E., "A study of the relationships between perceived organizational stratification and individual job satisfaction and adaptiveness in hospital laboratories," AMJ Med Technol, vol. 43, pp. 1135-1143, 1977.

[4] Freeborn D. K. and Hooker R. S., "Satisfaction of physician assistants and other non-physician providers in a management care setting," Public health Rep, vol. 110, pp. 714-719, 1995.

[5] Herzberg F., et al., "The motivation of work $2^{\text {nd }}$ edition," Nerw York, John Wiley and sons, 1963.

[6] Hackman J. F. and Oldham G. R., "Development of the job diagnostic survey," J Appl psycho, vol. 60, pp. 159-170, 1975.

[7] Longest B. J., "Management practices for the Health professional," $4^{\text {th }}$ edition Norwalk, Appleton and Lange, 1990.

[8] Maslow A., "Motivation and personality," 2nd edition, New York, Harper and Row, 1970.

[9] Hackett R. D. and Guion R. M., "Reevaluation of absenteeism-job satisfaction relationship," Organizational behaviour and decision making process, pp. 340-381, 1985.

[10] Griffeth R. W., et al., "Meta analysis of antecedents and correlates of employee turn over: update, moderator tests and research implications for the next millennium," Journal of management, vol/issue: 26(3), pp. 463-488, 2000.

[11] Deary I. J., et al., "Models of Job related stress and personal achievement among consultant doctors," $\mathrm{Br} J$. Psychology, vol. 87, pp. 3-29, 1996.

[12] Kirkcaldy B., et al., "The influence of type A behaviour and locus of control upon job satisfaction and occupational Health, Personality and individual differences," vol/issue: 33(8), pp. 1361-1371, 2002.

[13] A. Fisher, et al., "Handbook for Family Planning Operations Research Designs (2 ${ }^{\text {nd }}$ Edition)," New York, Population council, 1998.

[14] F. R. Ssengooba and C. E. Hongoro, "Human resources for health in decentralized Uganda: development and implications for health system research," Kampala, Institute of Public Health, Makerere University, 2005.

[15] J. Mtengezo, "Improving Nurse Retention: Factors influencing job satisfaction of All cadres of Nurse in Machinga District," University of Medicine, Malawi, 2008.

[16] B. Kalisch, et al., "Nursing staff teamwork and job satisfaction," Journal of Nursing management, vol. 18, pp. 938$947,2010$.

[17] J. McCann, et al., "Servant leadership employee satisfaction and organizational performance in Rural Community Hospitals," International journal of Business and management, vol/issue: 9(10), 2014.

[18] M. Lorber and S. Savic, "Job satisfaction of nurses and identifying factors of job satisfaction in Slovenian Hospitals," Croat med j., vol. 53, pp. 263-70, 2012.

[19] M. Ali and F. Wajidi, "Factors influencing job satisfaction in public health care sectors of Pakistan," Global journal of Management and Business Research Administration and Management, vol/issue: 13(8), 2013.

[20] M. Mengistu and A. Bali, "Factors associated to job satisfaction Among Healthcare Workers at Public Hospitals of West Shoa Zone, Oromia Regional State, Ethiopia: A cross-sectional study," Science journal of public health, vol/issue: 3(2), pp. 161-167, 2015.

[21] J. J. Ayomolowo, et al., "Job satisfaction and work environment of primary Health care Nurses in Ekiti State, Nigeria: an exploratory study," International journal of caring sciences, vol/issue: 6(3), 2013.

[22] M. Adamson and F. Maseko, "Survival and retention strategies for Malawian health professionals," Regional Network for equity in health in Southern Africa, 2005.

[23] A. Alijuhani and N. Kishk, "Job satisfaction among primary Physicians and Nurses in Al-Madinah AlMunawwara," The journal of the Egyptian Public Health Association (JEPHAss), vol/issue: 81(3-4), 2006. 


\section{BIOGRAPHIES OF AUTHORS}

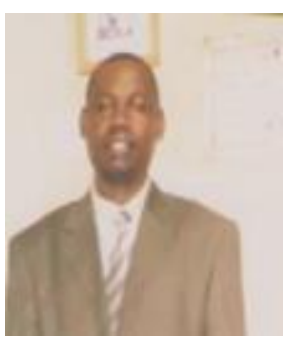

Anthony Wambua Mathulu (Bsc. Public Health, Master in Community Health), Unit Head, Ambulance Services, Department of Health, Government of Makueni County, Kenya, P.O Box 89,90300, Wote, Kenya. E-mail:mathulu@yahoo.com;amathulu@gmail.com; Tel:254 0721672634,0735622286

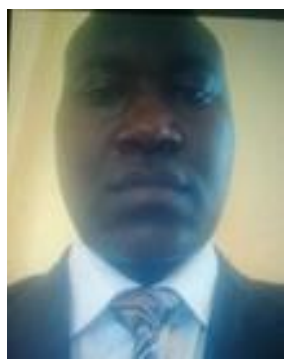

Bernard Wambua Mbithi (Bsc. N, MPH), Lecturer, School of Nursing, JomoKenyatta, University of Agriculture and Technology, Kenya, P.O Box: 62000-00200, Nairobi. E- mail: bwmbithi@yahoo.co.uk; Tel:254 0722321945 